\title{
Regression Periods in Infancy: A Case Study from Catalonia
}

\author{
Marta Sadurní and Carlos Rostan \\ University of Girona
}

\begin{abstract}
Based on Rijt-Plooij and Plooij's (1992) research on emergence of regression periods in the first two years of life, the presence of such periods in a group of 18 babies (10 boys and 8 girls, aged between 3 weeks and 14 months) from a Catalonian population was analyzed. The measurements were a questionnaire filled in by the infants' mothers, a semi-structured weekly tape-recorded interview, and observations in their homes. The procedure and the instruments used in the project follow those proposed by Rijt-Plooij and Plooij. Our results confirm the existence of the regression periods in the first year of children's life. Inter-coder agreement for trained coders was $78.2 \%$ and within-coder agreement was $90.1 \%$. In the discussion, the possible meaning and relevance of regression periods in order to understand development from a psychobiological and social framework is commented upon.

Key words: regression periods, child development, brain system development
\end{abstract}

Nuestro trabajo estudia los periodos de regresión en la infancia. A partir del trabajo de investigación de Rijt-Plooij y Plooij (1992) sobre la emergencia de periodos de regresión en los dos primeros años de vida, se analizó la presencia de estos periodos en un grupo de 18 niños (10 niños y 8 niñas) de una población catalana. La edad de los niños estaba comprendida entre las 3 semanas y los 14 meses. Los instrumentos de recogida de información fueron un cuestionario respondido por la madre del bebé, una entrevista semiestructurada registrada en grabadora y observaciones realizadas en casa de los sujetos. El procedimiento y los instrumentos usados en el proyecto siguen los propuestos por RijtPloij y Plooij en su investigación original. Nuestros resultados confirman la existencia de periodos de regresión en el primer año de vida infantil. La concordancia entre observadores independientes entrenados fue del $78,2 \%$ y la intraobservador fue del $90,1 \%$. Se comenta el significado que pueden tener los periodos de regresión y su interés para avanzar en la comprensión del desarrollo en un marco psicobiológico y social.

Palabras clave: Periodos de regresión, desarrollo infantil, desarrollo del sistema cerebral

This study was funded by a grant from The Ministry Of Education And Sciences (Pr95-11). The Ministry Of Education And Science also funded the II Symposium on Regression and Transition in Early Infancy, held in the University of Girona (Spain), with a grant (C097-0482).

The authors are grateful to H.H.C. van de Rijt-Plooij and F.X. Plooij for their constructive feedback. We wish to acknowledge and express our affection for Aaron Cicourel for his review and suggestions. Mónica González, Sergi Pascual, Josep Garre, and Pau Garcia were our collaborators.

The first version of this paper was presented at the "I Research Conference about Regression Periods" in Gothenburg, Sweden (October 10-11, 1997).

Correspondence concerning this article or requests for a complete description of the instruments used should be addressed to Dra. Marta Sadurní, Departamento de Psicologia. Facultad de Ciencias de la Educación. Universidad de Girona. Emilio Grahit, 77.1007 Girona (Spain). E-mail: msadurni@zeus.udg.es 
Development has traditionally been defined as a process of both quantitative and qualitative changes and transformations, which take place continuously and gradually in the human organism. These irreversible and cumulative transformations make the organization levels more and more complex. Developmental scientists have devoted much effort throughout the history of developmental psychology to analyze the nature of the changes of state or functioning that occur in the infant's mind which, in turn, facilitate the increasing complexity of behavior. These are basic issues and questions in developmental psychology. This research paper provides more data and some reflections on some of the current controversies: the study of transition and regression periods in the process of development and understanding the origin and the importance of social interaction in the learning process.

The traditional dichotomy between continuity-discontinuity in the development processes is becoming relevant in the light of the interesting data provided by many current studies. Continuity in the developmental processes has traditionally been presented as a succession of different structural and functional levels, which imply background homogeneity underlying the manifest heterogeneity. Nevertheless, as Fisher (1983) suggested, there is evidence of major reorganizations in psychological development. These reorganizations appear to be marked by discontinuities, that is, sudden spurts or changes in the behavior patterns. There has been much research on the qualitative changes occurring in the process of development, known in the literature as transitions (Connell \& Furman, 1984; Elman et al., 1996; Fisher, Pipp, \& Bullock, 1984; Fisher \& Rose, 1994; Geert, 1991, 1997; KarmiloffSmith, 1994; Johnson, 1997; Magnusson \& Cairns, 1996; McCall, Eichnor, \& Hogarthy, 1977; Reznick, Corley, \& Robinson, 1997; Schore 1994; Thelen \& Smith, 1994; Towen, 1998; Trevarthen, 1982a, 1995).

The concept of transition refers to those changes in the biological, neural, or psychological processes that take place in the first years of life and which lead to clear developmental progress. From this perspective, the concept of transition involves two types of changes: changes in overt behavior and changes in the structures and processes underlying behavior. The rapid developmental changes that take place in the first two years of life occur simultaneously with the synaptogenesic process. One could, therefore, infer that the reorganization of neural structures, which takes place at the early stages, plays a role in the emergence of the various infancy capacities. In fact, Elman et al. (1996) describe what they call progressive events as "changes in neural organization that come about by adding new structure." Such changes include the birth and proliferation of neurons, their migratory changes, or the sprouting and extension of neural processes. Nevertheless, according to the above-mentioned authors and the general consensus of current developmental psychology, many of the changes in neural connections are also a result of the learning process itself or of external events.
Spitz's pioneer study (1959) refers to three transitional periods during the first 18 months of life. Subsequently, McCall et al. (1977) proposed the existence of four periods, emerging at 2, 7, 13, and 21 months. These periods were registered by Schaffer (1984) and corroborated by Fisher et al. (1984), Trevarthen (1982b, 1984), and Lampl and Emde (1983). Further research has shown new likely transitional periods. Rijt-Plooij and Plooij (1992) observed other significant spurts around 4_-5 months; other research revealed significant developmental progress at the ages of 9-13 (Plooij \& Rijt-Plooij, 1989; Zelazzo, 1982) and 18-24 months (Fisher \&Rose, 1994; Schore, 1994).

Recent findings indicate that this discontinuity does not only imply developmental gaps but also regressions and the disappearance of apparently acquired behaviors and capacities. Some of these capacities reappear later on and others definitely cease to be functional. Bever's (1982) research revealed regressive mechanisms in linguistic and cognitive development, due to internal restructuring of knowledge. Geert (1991), likewise, proposed regressive mechanisms in speech and general developmental process. Thelen and Smith (1994) accounted for the disappearance of reflex behaviors such as automatic walking, as "adaptive solutions to ontogenetic changes in life's demands." Thus, there are different types of regressions in the developmental process but, implicitly or explicitly, all of them refer to the notion of regression to previous behavioral structures or patterns.

In this article, we are particularly interested in a certain type of regressions that belong to the emotional domain and that occur repeatedly during the first 2 years of infancy. RijtPlooij and Plooij (1992) described them as "temporary decrease/disappearance of the growing independence of the baby as measured through mother-infant body contact, combined with an increase in crying." During these periods, infants present behaviors that mothers do not hesitate to qualify as "difficult or unstable." Babies easily lose their tempers and cry, sleep is often disrupted, some of the infants lose their appetites, and all of them display an increased need of body contact with their mothers. In terms of Bowlby's (1969) well-known theory, during those periods, attachment is reactivated or grows markedly stronger. Rijt-Plooij and Plooij observed ten regression periods in the 2 first years of life at 5, 8, 12, 17, 26, 36, 44, 53, 61-62, and 72-73 weeks. Moreover, these authors stated that similar behaviors can be observed in primate mammals (Rijt-Plooij \& Plooij, 1987). We will not delve into the difficult topic of behavior generalizations between primates and humans in this article.

The basic purpose of our study was to verify whether the regression periods described by Rijt-Plooij and Plooij (1992, 1993) appeared in a sample of infants in our country. Furthermore, we examined whether the ages at which they emerged and their characteristics were likewise similar to those observed by these authors.

Children become more independent as they grow older. This is seen in their increased interest in their surroundings 
and a consequent decrease in mother-child body contacts. The frequency of body contact will continue to diminish as the child grows older. However, we expect to find an increase in mother-child body contact during the difficult moments described as regression-periods. Therefore, our hypothesis was that the observed frequency of mother-child body contact coinciding with a regression period will be either higher than, or at least of the same frequency as, mother-child body contact observed the previous week that did not coincide with a regression period.

\section{Method}

\section{Participants}

The group of participants was made up of 18 infants (10 boys and 8 girls) aged between 3 weeks and 14 months, and their respective mothers, distributed in 4 mother-infant cohorts. Each cohort was made up of 5 dyads and included an interval of 5 months, as shown in Table 1. However, two mothers (one from the first cohort and one from the second) wished to go on participating as subjects of the following cohort, as can be seen in Figure 2. That is why there are 20 dyads according to the cohorts, but only 18 participants. The babies were from Catalonian families of medium socio-economic and cultural class. Only 1 baby belonged to a monoparental family, with a single mother.

All the babies observed were full-term except for one girl who was born at seven months and whom we studied according to her age if she had been full-term. No babies presented either serious health problems or developmental phase-lags regarding their chronological age. Ten of the babies were firstborn, 7 had an older sibling, and 1 had two older siblings.

The families recruited for the research were acquaintances of members of our research group or of students from our University, who contacted them. Their participation was voluntary and they were not paid.

\section{Measurements}

The following instruments were used to gather information:
Regression Periods Maternal Questionnaire (Rijt-Plooij \& Plooij, 1993). We used a Spanish adaptation. The translation was carried out with the suggestions made by a group of mothers with babies of the same ages as the ones in our research. The questionnaire was filled in by the infants' mothers and was collected weekly.

A semi-structured weekly tape-recorded interview. In this interview, we asked the mothers about their experience with their babies in the course of the week. We completed the information provided by the mothers spontaneously with a series of questions that, indirectly and informally, revealed the infant's development. Examples of these questions are: "Has your child cried more easily or persistently this week?" "Has your child demanded more attention?" "Has your child slept less or slept more restlessly?" "Has your child awakened more often during the night?" "Has your child eaten less?" "When you play or communicate with your child, has he or she vocalized less (from week 15)?"

Observations. We carried out a three-hour observation every two weeks during the two first months, and once a month as of that age. The aim of the observation was to corroborate the information provided by the mother by means of our own perceptions. For this purpose, we designed a check-sheet where the observer wrote down the frequency and the degree of mother-infant body contact, depending on whether the child was on her lap, in her arms, or without contact (Rijt-Plooij \& Plooij, 1992).

Data-gathering about the presence or absence of regression periods was limited to the questionnaire and the semi-structured interview. Observations were only used to check the reliability of the mother's information by means of chi-square.

\section{Procedure}

Rijt-Plooij and Plooij (1992) gathered the data for their study about regression periods by means of a questionnaire filled in by the mothers and a check-sheet in which the mother was asked to record every half-hour the infant's whereabouts and the kind of interaction they were involved in. Two of the dyads that participated in their study were also observed directly, using an OS-3 electronic event-recorder computer. This was done to validate the maternal reports (for the original instruments, see Rijt-Plooij \& Plooij, 1992)

Table 1

Distribution per periods of the cohorts studied

\begin{tabular}{lccc}
\hline & Age & Periods by weeks & No. of dyads observed \\
\hline 1 cohort & 3 weeks -5 months & $3-20$ & 5 \\
2 cohort & $3-8$ months & $12-33$ & 5 \\
3 cohort & $6-11$ months & $24-44$ & 5 \\
4 cohort & $9-14$ months & $36-56$ & 5 \\
& & & Total $=20$ dyads \\
\hline
\end{tabular}


In our study, we used an adaptation of the questionnaire designed by Rijt-Plooij and Plooij (1992). We substituted the check-sheet with an interview of the mothers each time the questionnaires were collected. The reason for this was that we considered that asking the volunteer mothers to fill in a check-sheet every half-hour was excessive. In order to validate the maternal reports, we observed all the dyads that participated in our investigation. (The electronic eventrecorder was not available in this study.)

The procedure used in our project follows the proposal by Rijt-Plooij and Plooij (personal communication, November 1995) for the study of regression periods. The research design was transversal and longitudinal. For this purpose, the 18 dyads were divided into cohorts of 5 months, as displayed in Table 1. However, two of them were of 8 months, covering the following cohort, as already mentioned in the Participants section.

The mothers were not informed about the exact purpose of the study. They were told in broad terms that the aim was to study the infant's development. In order to analyze the data, we used a multiple case study, which allows intraindividual comparison throughout the period of study. Subsequently, we examined whether the supposed signs of regression periods correlated with the moments of behavioral qualitative change in all babies.

The criteria to rate a period as a regression period, on the basis of maternal reports from the questionnaires and interviews, was the same one as described by RijtPlooij and Plooij (1992). A regression period was defined by the coexistence of three of the following behavioral categories:

1. An increase in the bodily contact between mother and child. The mother stated that the infant no longer amused him- or herself on his or her own and only seemed to calm down when lifted up or held on the mother's lap.

2. An increase in crying and irritable behaviors. The infant was described as extremely sensitive and vulnerable. The most frequently repeated sentences in our records were "I don't know what's the matter wish him/her. I don't know how to soothe him/her."

3. The addition of a third troublesome behavior such as decrease in amount of sleep, fear of people, childish behaviors, decrease in the amount of food-intake at one meal, problems with changing/dressing, decrease in activity, peak in cuddling mother or in cuddling objects.
Some mothers try to find an explanation for these troublesome behaviors, concluding that perhaps the child doesn't feel well or "is catching something." Visits to the pediatrician are not rare during these episodes. Those cases in which some kind of pain or illness in the infant's organism actually showed up were not classified as regression periods.

Following the criteria for rating a period as a regression period, we calculated inter- and within-coder categorization reliability, based on the questionnaires and interviews. Intercoder agreement for trained coders was $78.2 \%$; within-coder agreement was higher, $90.1 \%$.

We also carried out observations of mother-child contact in their own homes, with the aim of checking to see whether the mothers' information (from questionnaires and interviews) coincided with our observations and, in this way, to establish the reliability of the information provided by the mothers. The statistical measure used was the chi-square test, as detailed below.

We also used chi-square to test whether there were differences in the frequency of mother-child body contact, according to our observations, and whether or not the child was going through a regression period, according to the analysis of the mothers' information.

The data from the observations are displayed in Table 2 , which shows that, as expected, there were 27 observations carried out during a regression period during which the frequency of mother-child body-contact increased with regard to the observations carried out during a nonregression period. On the contrary, in 5 observations that were also carried out during a regression period, there was a decrease in body-contact in relation to the previous observation. Moreover, in 9 observations carried out during nonregression periods, the frequency of body-contact increased in relation to the previous observation, as though it were a regression period. And the 54 observations during a nonregression period also showed a decrease in body-contact frequency with respect to the previous observation.

The chi-square test applied revealed a value of $\chi^{2}(1, N$ $=95)=41,38, p<.001$. This shows that the observed frequency of mother-child body contact coinciding with a regression period will be higher than mother-child body contact not coinciding with a regression period. We can also consider that the information provided by the mothers is reliable.

Table 2

Body-Contact Changes during the Observations

\begin{tabular}{lccc}
\hline & Increased Body-Contact & Decreased Body-Contact & Total Cases \\
\hline Observations during regression periods & 27 & 5 & 32 \\
Observations during nonregression periods & 9 & 54 & 63 \\
Total Cases & 36 & 59 & 95 \\
\hline
\end{tabular}




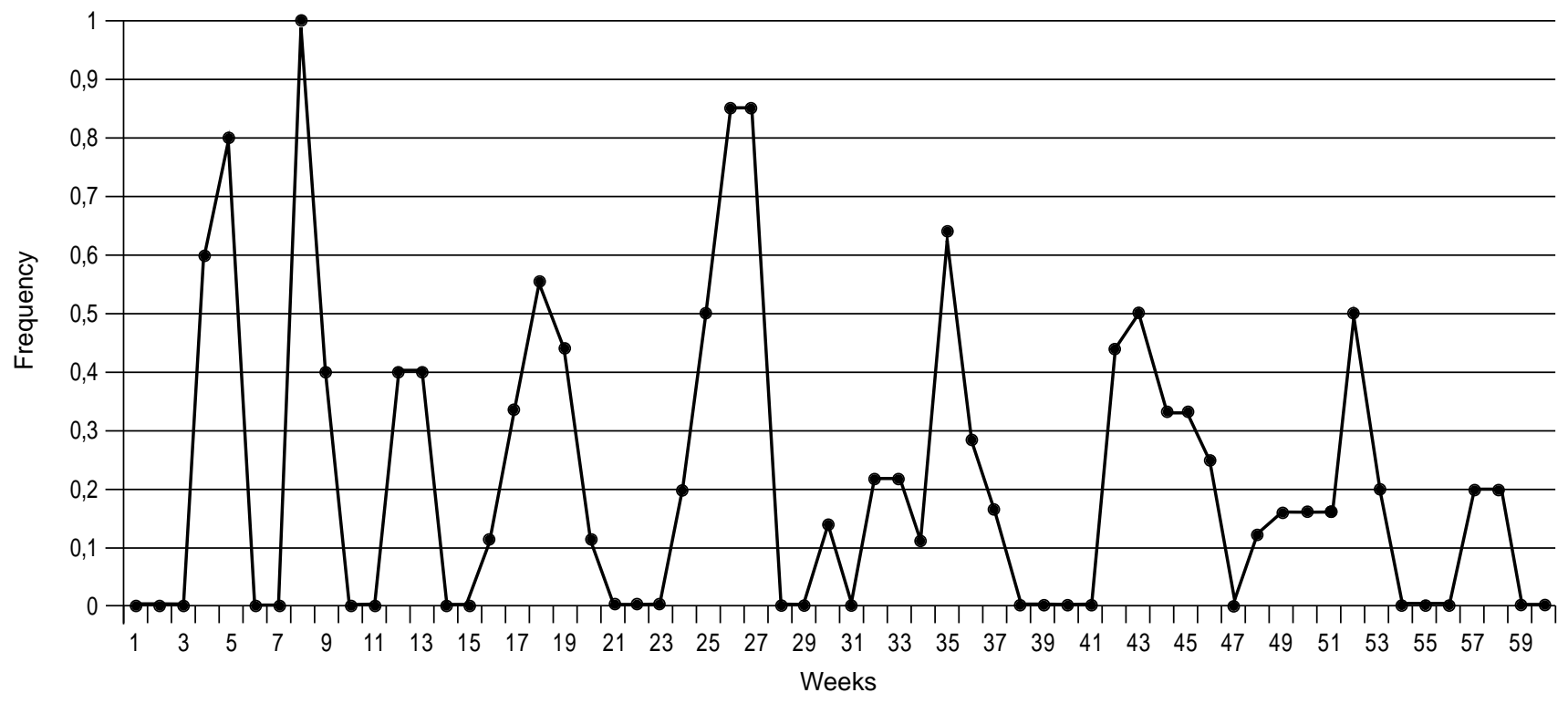

Figure 1. Regression period frequency per week.

Results

Figure 1 shows a graphic version of the results according the maternal reports (questionnaires and interviews). The maximum frequency of the regression periods in our research appeared at the following ages: 5, 8, 12-13, 18, 26-27, 35, 43 , and 52 weeks. The mean duration of a regression period was 2 weeks, with a range of 1-4 weeks.

In Figure 2 can be seen the location of the regression periods, child by child.

We wish to emphasize two aspects: the similar description of the behaviors that characterize a regression period and the regularity with which they emerge. There were also some differences observed among the dyads studied. Whereas some children concentrated this troublesome period, in other children, the instability tended to be more prolonged over time. Some children appeared to be calmer than others, even within the same regression period, and the mothers experienced these moments with varying degrees of annoyance and difficulty. The regression periods seemed to be more concentrated in the first weeks and more dispersed in the last ones. Although this dispersion did not affect the continuous distribution of such periods, this fact should be considered more carefully

Despite the fact that the percentages shown in Figure 1 do not reach $100 \%$, a closer look at Table 3 reveals that nearly all the mothers reported a regression period at approximately these ages. Only one mother did not report a regression period during the 12-13-week and 41-46-week intervals.

Figure 3 shows data reported by Rijt-Plooij and Plooij (1992). Upon comparing these authors' data with our own, it can be seen that the number of regression periods observed throughout the first 60 weeks of the infant's life coincides: In both studies, there were eight regression periods. The weeks around which regression periods are distributed coincide in four of the observed periods. In the other four periods, they occurred either a week sooner or later.

Despite the similarities of the two studies, we point out that, in our research, five of the regression periods ranged between $40 \%$ and $62 \%$, whereas the maximal percentage in Rijt-Plooij and Plooij's (1992) work was not lower than $80 \%$. On the other hand, our regression-period distribution (see Figure 1) is more concentrated than in the study by these authors.

Table 3

Intervals (in Weeks) and Frequency of Reported Regression Periods

Interval in weeks

\begin{tabular}{lcccccccc} 
& $4-5$ & 8 & $12-13$ & $17-19$ & $26-27$ & $33-36$ & $42-46$ & $49-53$ \\
\hline Percentage of mothers who reported regression periods & 100 & 100 & 80 & 100 & 100 & 100 & 90 & 100 \\
\hline
\end{tabular}




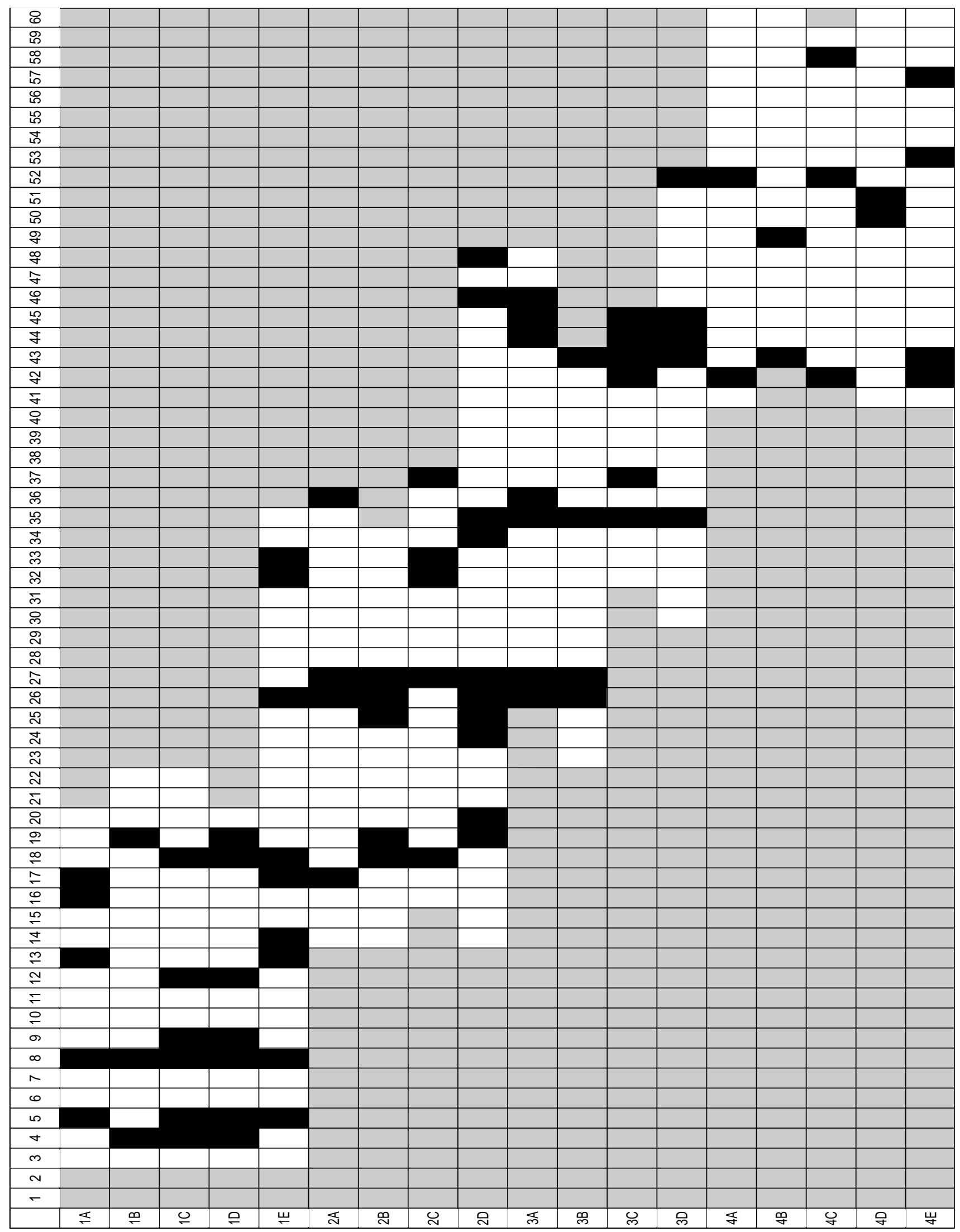

Figure 2. Distribution of regression periods according to each mother and week. Columns represent the weeks. Rows represent each case, with the number corresponding to the cohort and the letter to the child. 


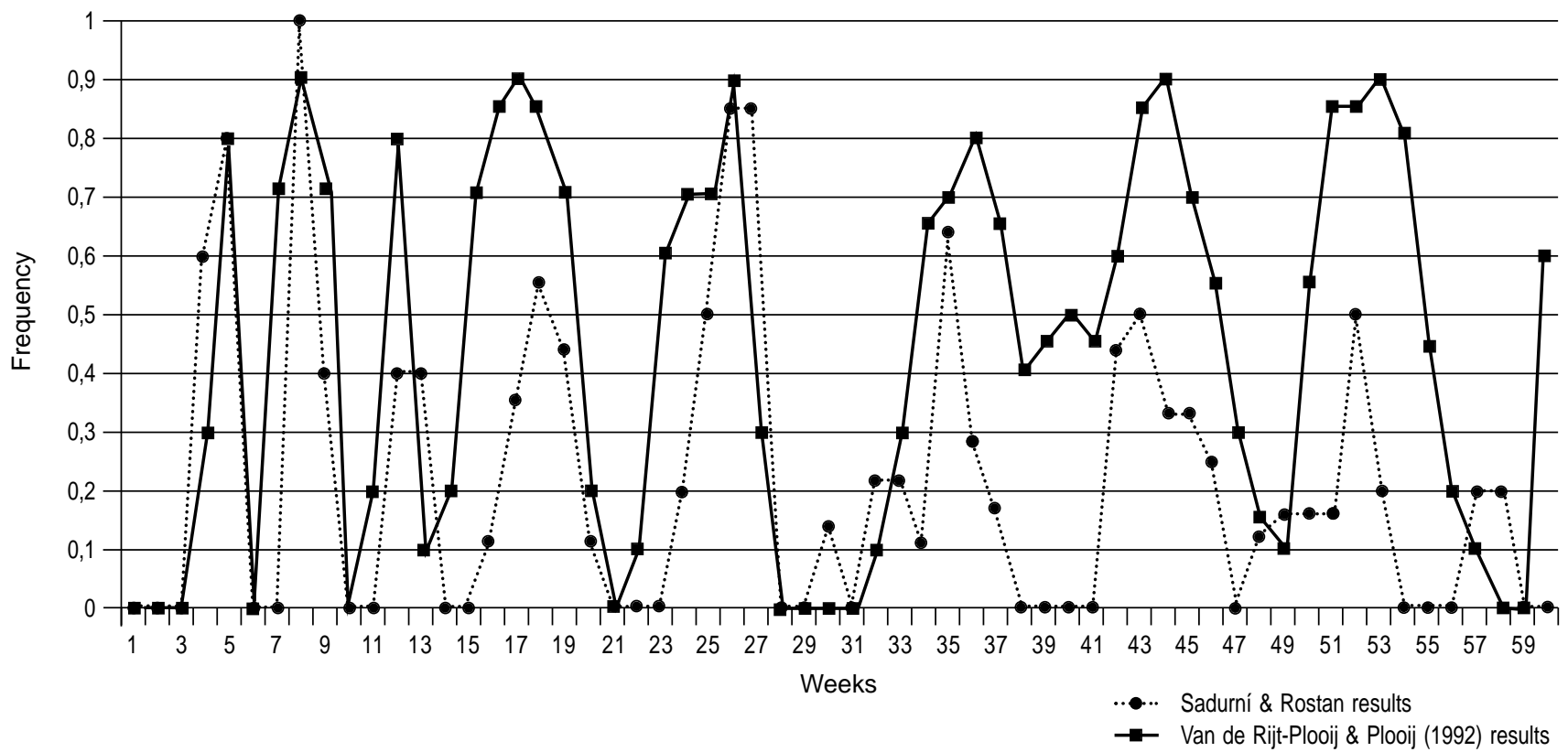

Figure 3. Comparative graphics of regression periods found in our study and in the study by Rijt-Plooij and Plooij (1992).

\section{Discussion}

The purpose of this study was to replicate the studies carried out by Rijt-Plooij and Plooij (1992) about the existence of regular periods in children's first year, characterized by emotional disturbances, such as an increase in crying and in demands for attention. These behaviors produce an increase in the physical contact between the mother and her child. Most children show other troublesome behaviors that seem to vary according individual characteristics. According to these authors, among the most common are a decrease in time spent sleeping, lack of appetite, and increased activity, although in some children, a decrease in activity is observed. According to Rijt-Plooij and Plooij's hypothesis, these periods are predictable. In other words, all children experience them at regular and predicable ages (in weeks).

Our study confirms the results of these authors, with small variations in the weeks during which our subjects experienced regression periods. Nevertheless, the distribution of regression periods in our study is more diffuse (the time of the regression periods is not so concentrated in a peak week) than that reported by Rijt-Plooij and Plooij (1992). One explanation could be the different instruments used in our research, resulting in different processes of gathering information. In our study, as mentioned, we used a questionnaire and a directed interview with the mother. In the original Dutch work, information was gathered mainly by means of a check-sheet in which the mother reported any change in the child's behavior. To a certain extent, it is logical for there to be a difference between the mothers' reports during the conversation and the detailed record of a daily check-sheet. However, the concordance between both studies is high and suggests a regular pattern in the existence of regression periods and the ages at which they appear.

Such regularity suggests a strong "genetic timing," although we point out that, according to Hoffer (1987) and other researchers, the social relation that is established between a mother and her child also plays a role in setting the child's biological clock. On the other hand, despite regularities, each mother-child dyad is singular in relation to the group studied. When analyzing the figures, it can be seen that the duration of regression periods differs from one child to another. For some of them, those moments of difficulty seem to be concentrated in a brief time-interval, whereas other children persist in manifesting the typical troublesome behaviors. Our study suggests that, before accepting a biological constraint, more research is required about the effects of maternal behaviors on the temporal pattern of regressions periods.

Another discussion topic is the relation between regression periods and brain development. It is known that various areas of the human brain continue to develop at different intervals during the postnatal period (Chugani, 1994; Chugani, Phelps, \& Mazziota, 1987; Dehane-Lambertz \& Dehane, 1997; Huttenlocher, 1990, 1994; Huttenlocher \& Dabholkar, 1997; Tatcher, 1992, 1997; Yakolev \& Lecours, 1967). This trait of human brain development has lead several authors (Lecours, 1982; Prechtl, 1982; Trevarthen, $1982 \mathrm{~b})$ to speculate that regression periods could be interpreted as behavioral signs of brain reorganization that the infant experiences during the postnatal development process. Rijt-Plooij and Plooij (1987) suggested that the 
maturing experience would cause a loss of homeostatic regulation in the infant. The child cannot restore control alone, hence the intrinsic need to activate systems that guarantee the necessary attention and care for the infant's organism during a phase of instability and change. These mechanisms are the regression periods. These authors (Plooij $\&$ Rijt-Plooij, 1994) propose that during regression periods, the infant's mind is very sensitive and open to external stimuli, particularly to the socio-affective stimuli proceeding from the mother. By crying and expressing uneasiness, the infant seeks, and usually gets, more maternal attention.

Developmental psychology is carrying out an great effort to relate children's observable behaviors to neuroscience. However, our discipline has a long way to go before these hypotheses become scientific realities. Our study shows the existence of regression periods in the first year of children's life. However, more studies about regression periods should be carried until a solid body of data is gathered and carefully considered. If the temporal patterns of regression periods are corroborated, the next stage in this research should verify whether or not regression periods indicate transition periods, and also whether regression periods and transition variations in the course of child development are the manifestation of cerebral reorganization, as claimed by Rijt-Plooij and Plooij (1992) in their theoretical model.

\section{References}

Bever, Th.G. (1982). Regression in the service of development. In Th. G. Bever. (Ed.), Regressions in mental development: Basic phenomena and theories (pp. 153-188). Hillsdale, NJ: Erlbaum.

Bowlby, J. (1969). Attachment. London: Hogarth Press.

Chugani, H.T., Phelps, E.M., \& Mazziotta, J.C. (1987). Positron emission tomography study of human brain functional development. Annals of Neurology, 22, 487-497.

Chugani, H.T. (1994). Development of regional brain glucose metabolism in relation to behavior and plasticity. In G. Dawson \& K.W. Fisher (Eds.), Human behavior and developing brain (pp. 153-206). New York: Guilford Press.

Connell, J.P., \& Furman, W. (1984). The study of transitions: Conceptual and methodological issues. In R.N. Emde \& J.H. Harmon (Eds.), Continuities and discontinuities in development (pp. 153-173). New York: Plenum Press.

Dehaene-Lambertz, G., \& Dehaene, S. (1997). In defense of learning by selection. Neurobiological and behavioral evidence revisited. Behavioral and Brain Science, 20, 561-562.

Elman, J.L., Bates, E.A., Johnson M.H., Karmiloff-Smith, A., Parisi,, D., Plunkett, K. (1996). Rethinking innateness: A connectionist perspective on development. Cambridge, MA: MIT Press.

Fisher, K.W, Pipp, S.L., \& Bullock, D. (1984). Detecting development discontinuities: Methods and measurement. In R.N. Emde \& J.H. Harmon (Eds.), Continuities and discontinuities in development (pp. 95-121). New York: Plenum Press.
Fisher, K.W., \& Rose, S.P. (1994). Dynamic development of coordination of components in brain and behavior: A framework for theory and research. In G. Dawson \& K.W. Fisher (Eds.), Human behavior and the developing brain (pp. 3-66). New York: Guilford Press.

Fisher, K.W. (Ed.). (1983). New directions for child development: Levels and transitions in children's development. San Francisco, CA: Jossey-Bass.

Geert, P. van (1991). A dynamic system model of cognitive and language growth, Psychological Review, 98, 3-53.

Geert, P. van (1997). Variability and fluctuation: A dynamic view. In C. Amsel \& K.A. Renninger (Eds.), Change and development: Issues and theory, methods and applications (pp. 193-212). Mahwah, NJ: Earlbaum.

Hoffer, M.A. (1987). Early social relationships: A psychobiologist's view. Child Development, 58, 633-647.

Huttenlocher, P.R. (1990). Morphometric study of human cerebral cortex development. Neuropsychologia, 28, 517-527.

Huttenlocher, P.R. (1994). Synaptogenesis, synapse elimination, and neural plasticity in human cerebral cortex. In Ch.A. Nelson (Ed.), Threats to optimal development. The Minnesota Symposia on Child Psychology, Vol. 27. (pp. 35-54). Hillsdale; NJ: Earlbaum.

Huttenlocher, P.R., \& Dabholkar, A.S. (1997). Developmental anatomy of prefrontal cortex. In N.A. Krasnegor, G.R. Lyon, \& P.S. Goldman-Rakic (Eds.), Development of prefrontal cortex (pp. 69-84). Baltimore, MD: Brookes.

Johnson, M.H. (1997). Developmental cognitive neurosciences: An introduction. Oxford, UK: Blackwell.

Karmiloff-Smith, A. (1994). Précis of Beyond modularity: A developmental perspective on cognitive science. Behavioral and Brain Science. 17, 693-745.

Lampl, M. \& Emde, R.N. (1983). Episodic growth in infancy: A preliminary report of length, head circumference and behavior. In K.W. Fisher (Ed.), New directions for child development: Levels and transitions in children's development. San Francisco, CA: Jossey-Bass.

Lecours, A.R. (1982). Correlates of developmental behavior in brain maturation. In Th.G. Bever. (Ed.), Regressions in mental development: Basic phenomena and theories (pp. 103-116). Hillsdale, NJ: Erlbaum.

Magnusson, D., \& Cairns, R.B. (1996). Developmental science: Toward a unified framework. In R.B. Cairns, G.H. Elder, \& E.J. Costello (Eds.), Developmental science (pp. 7-30). Cambridge, NY: Cambridge University Press.

McCall, R.B., Eichnor, D.H., \& Hogarty, P.S. (1977). Transitions in early development. Monographs of the Society for Research in Child Development, 42, (3, Serial No 171).

Plooij, F.X., \& Rijt-Plooij, H.H.C. van de (1989). Evolution of human parenting. Canalization, new types of learning, and mother-infant conflict. European Journal of Psychology of Education, 4, 177-192.

Plooij, F.X., \& Rijt-Plooij, H.H.C. van de (1994). Learning by instincts, developmental transitions, and the roots of culture in infancy. In R.A. Gadner A.B. Chiarelli, B.T. Gardner, \& F.X. 
Plooij (Eds.), The ethological roots of culture (pp. 357-373). Dordrecht, The Netherlands: Kluwer.

Prechtl, H.F.R. (1982). Regressions and transformations during deurological devleopment. In Bever, Th.G (Ed.), Regressions in mental development: Basic phenomena and theories (pp.103116). Hillsdale, NJ: Earlbaum.

Reznick, J.S., Corley, R., \& Robinson, J. (1997). A longitudinal twin study of intelligence in the second year. Monographs of the society for research in child development, 62 (1, Serial No. 249).

Rijt-Plooij, H.H.C. van de, \& Plooij, F.X. (1987). Growing independence, conflict and learning in mother-infant relation in free-ranging chimpanzees, Behavior, 101, 1-86.

Rijt-Plooij, H.H.C. van de, \& Plooij, F.X. (1992). Infantile regressions: Disorganization and onset of transition periods. Journal of Reproductive and Infant Psychology, 10, 129-149.

Rijt-Plooij, H.H.C. van de, \& Plooij, F.X. (1993). Distinct periods of mother-infant conflict in normal development: Sources of progress and germs of pathology. Journal of Child Psychology and Psychiatry, 34, 229-245. [Spanish translation of questionnaire in C. Rostan, Análisis de los periodos de regresión y transición durante el primer año de vida. Unpublished doctoral dissertation, University of Girona, Spain. (1998).]

Schaffer, H.R. (1984). The child's entry in the social world. London: Academic Press

Spitz, R.A. (1959). A genetic field theory of ego formation: Its implication for pathology. New York: International Universities Press.

Schore, A.N. (1994). Affect regulation and the origin of the self: The neurobiology of emotional development. Hillsdale, NJ: Earlbaum.

Tatcher, R.W. (1992). Cyclic cortical reorganization. Brain \& Cognition, 20, 24-50.

Tatcher, R.W. (1997). Human frontal lobe development. A theory of cyclical cortical reorganization. In N.A. Krasnegor, G.R.
Lyon, \& P.S. Goldman-Rakic (Eds.), Development of Prefrontal cortex (pp. 85-113). Baltimore, MD: Brookes.

Thelen, E., \& Smith, L.B. (1994). A dynamic systems approach to the development of cognition and action. Cambridge, MA: MIT Press.

Towen, B.C.L. (1998). The brain development and function. Developmental Review, 18, 504-526.

Trevarthen, C. (1982a). The primary motives for cooperative understanding. In G. Butterworth \& P. Light (Eds.), Social Cognition: Studies of development of understanding (pp. 77109). Brighton, UK: Hasvester Press.

Trevarthen, C. (1982b). Basic patterns of psychogenetic change in infancy. In T.G. Bever (Ed.), Regression in mental development: Basic phenomena and theories (pp. 7-46). Hillsdale, NJ: Earlbaum.

Trevarthen, C. (1984). Emotions in infancy: Regulators of contact and relationships with persons. In K, Sherer \& P. Ekman (Eds.), Approaches to emotion. Hillsdale, NJ: Erlbaum.

Trevarthen, C. (1995). Contracts of mutual understanding: Negotiating meaning and moral sentiments with infants. Journal of Contemporany Legal Issues, 6, 373-406.

Yakolev, P.I., \& Lecours, A.R. (1967). The myelogenetic cycles of regional maturation of the brain. In A. Minkowski (Ed.), Regional development of the brain in early life (pp. 3-70). Oxford, UK: Blackwell.

Zelazzo, Ph, R. (1982). The year-old infant. A period of major cognitive development. In Th.G. Bever. (Ed.), Regressions in mental development: Basic phenomena and theories (pp. 4779). Hillsdale, NJ: Erlbaum.

Received February 28, 2000

Revision received February 15, 2001

Accepted February 23, 2001 